\title{
Urban Imperviousness Effects on Summer Surface Temperatures Nearby Residential Buildings in Different Urban Zones of Parma
}

\author{
Marco Morabito ${ }^{1,2, *}$, Alfonso Crisci ${ }^{1}$, Teodoro Georgiadis ${ }^{1}$, Simone Orlandini ${ }^{2,3}$, \\ Michele Munafò ${ }^{4}$, Luca Congedo ${ }^{5}$ (D), Patrizia Rota ${ }^{6}$ and Michele Zazzi ${ }^{6}$ \\ 1 Institute of Biometeorology, National Research Council, 50145 Florence, Italy; a.crisci@ibimet.cnr.it (A.C.); \\ t.georgiadis@ibimet.cnr.it (T.G.) \\ 2 Centre of Bioclimatology, University of Florence, 50144 Florence, Italy; simone.orlandini@unifi.it \\ 3 Department of Agrifood Production and Environmental Sciences, University of Florence, \\ 50144 Florence, Italy \\ 4 Italian National Institute for Environmental Protection and Research (ISPRA), 00144 Rome, Italy; \\ michele.munafo@isprambiente.it \\ 5 Department of Architecture and Design (DiAP), Sapienza University of Rome, 00185 Rome, Italy; \\ ing.congedo.luca@gmail.com \\ 6 Department of Engineering and Architecture (DIA), 43124 Parma, Italy; rotrizia@gmail.com (P.R.); \\ michele.zazzi@unipr.it (M.Z.) \\ * Correspondence: m.morabito@ibimet.cnr.it; Tel.: +39-055-522-6041
}

Received: 25 October 2017; Accepted: 21 December 2017; Published: 24 December 2017

\begin{abstract}
Rapid and unplanned urban growth is responsible for the continuous conversion of green or generally natural spaces into artificial surfaces. The high degree of imperviousness modifies the urban microclimate and no studies have quantified its influence on the surface temperature (ST) nearby residential building. This topic represents the aim of this study carried out during summer in different urban zones (densely urbanized or park/rural areas) of Parma (Northern Italy). Daytime and nighttime ASTER images, the local urban cartography and the Italian imperviousness databases were used. A reproducible/replicable framework was implemented named "Building Thermal Functional Area" (BTFA) useful to lead building-proxy thermal analyses by using remote sensing data. For each residential building $(n=8898)$, the BTFA was assessed and the correspondent ASTER-LST value (ST_BTFA) and the imperviousness density were calculated. Both daytime and nighttime ST_BTFA significantly $(p<0.001)$ increased when high levels of imperviousness density surrounded the residential buildings. These relationships were mostly consistent during daytime and in densely urbanized areas. ST_BTFA differences between urban and park/rural areas were higher during nighttime (above $1{ }^{\circ} \mathrm{C}$ ) than daytime (about $0.5^{\circ} \mathrm{C}$ ). These results could help to identify "urban thermal Hot-Spots" that would benefit most from mitigation actions.
\end{abstract}

Keywords: thermal infrared images; urban heat island; soil sealing; city; park; green areas; rural; heat

\section{Introduction}

Based on the global urban population prospects of the United Nations [1], since 2007, the urban population is higher than the rural one. In addition, future scenarios suggest that this gap is expected to continue to grow and about two-thirds of the world's total population will reside in urban areas by 2050 [1]. This pattern is already a reality in Europe, where more than $70 \%$ of people live in cities, towns and other urban settlements (generally small cities with fewer than 500,000 inhabitants). Continuous urban land expansion at rates much higher than population growth has led to a massive urban footprint on Europe. The rapid and often uncontrolled and/or unplanned urban growth is responsible for the 
continuous conversion of green, or generally other natural spaces, into artificial surfaces (soil sealing or imperviousness). This last phenomenon is defined as the permanent covering of soil by completely or partly impermeable artificial materials (e.g., asphalt, concrete, and brick) [2].

Imperviousness is the main cause of soil degradation in Europe [3]. It contributes to the progressive and systematic destruction of the natural landscape, increasing the risk of flooding (due to the water runoff rising) and water scarcity, and strengthens the climate change magnitude (influencing the carbon cycle). Moreover, it threatens the biodiversity (reducing or affecting habitats), causing a loss of fertile agricultural land and natural and semi-natural areas [4]. In particular, as urban settlements have been historically established next to the most fertile areas, soil sealing often affect the most fertile soils, in this way affecting European food security [2]. Urban areas are characterized by the highest degree of imperviousness and continuous built-up areas [5] with direct consequences on its microclimate. The high thermal conductivity and the heat storage capacity, often coupled with low solar reflectivity of most artificial impervious surfaces, cause alterations to the energy budget of the surfaces, increasing the sensible heat instead of the latent heat, and producing a generalized rise in the urban temperature. This situation significantly contributes to the well-known urban heat island (UHI) effect, represented by local surface and air temperatures in densely built-up city areas consistently higher than the temperatures observed in surrounding rural landscapes characterized by a greater density of pervious surfaces [6]. This phenomenon tends to create many critical conditions in the urban environment, among which the amplification of the urban heat load during summer heat-wave events [7,8] and significant increases of housing cooling loads and electricity consumption [9,10], are potential causes of harmful blackouts or brownouts. This situation is also associated with an exacerbation of thermal discomfort [11] and the higher levels of heat-related-mortality of vulnerable people living in densely built-up districts of urban areas than rural ones [12].

In urban thermal environment studies, the land surface temperature (LST) estimated by thermal infrared remote sensing techniques draws more attention than the air temperature measured by local meteorological stations for several reasons. Meteorological station networks allow discrete and generally scattered monitoring (often in suburban areas) representative of areas with determined physical characteristics, which hardly reflect the spatial air-temperature variation based on different surfaces that characterize the heterogeneous urban/suburban environments [13]. Then, thermal infrared remote sensing data have been extensively used in urban climate studies for analyzing the LST patterns and its association with built-up indicators [14-19].

The introduction of very high spatial resolution satellite images (i.e., IKONOS, Quickbird, and RapidEye) and more efficient image processing techniques implemented by GIS software tools have allowed the development of advanced technologies for better mapping and quantifying urban impervious surfaces [20-25]. A representative example in this context at European level is the Copernicus program (coordinated and managed by the European Commission with the fundamental contribution of the European Space Agency and the European Environmental Agency) that includes the acquisition of data from multiple satellites and the integration with field surveys (in situ data and services). Copernicus ensures the homogeneity of environmental monitoring in general, and in particular the land cover classification at European level [26]. As part of the Copernicus framework, several high-resolution layers were produced for specific purposes at the national level, with 2012, 2015 and 2016 as reference years. As an example, the Italian National Institute for Environmental Protection and Research (ISPRA: Istituto Superiore per la Protezione e la Ricerca Ambientale) developed very high-resolution maps of built-up surfaces (a binary indicator of urbanization) for the entire Italian territory [27,28]. These data were used in a recent study [29] to evaluate the relationships between built-up-surface densities and daily LST (daytime and nighttime) in several Italian cities. Modeling these relationships, useful urban maps have been developed visualizing the spatial footprint of imperviousness on urban microclimate. However, the easy access to remote sensed resources, coupled with a wider coverage and better spatial resolution of thermal infrared measurements, would allow more detailed urban analyses, as well as investigating the situation nearby buildings. Currently, 
only rare studies [30] used high-resolution thermal remotely imageries to deal with individual building structures. For this reason, the aim of the present study is to provide a framework, valid for an Italian urban summer context (Parma), able to investigate the relationships between the surface temperature nearby residential buildings, by using high-resolution thermal images (NASA-ASTER), and the surrounding imperviousness density assessed through the high-resolution Italian built-up-surfaces database provided by ISPRA. This study is based on the hypothesis that, during a generic summer day, the surface temperature nearby a residential building is influenced by its surrounding imperviousness density.

\section{Materials and Methods}

\subsection{Study Area and Summer Climate Characteristics}

This study was carried out on the inland city of Parma, a municipality with an area of about $260 \mathrm{~km}^{2}$ (small city size), an elevation of $55 \mathrm{~m}$, and almost 200,000 inhabitants (population density $740 / \mathrm{km}^{2}$ ) located in Northern Italy, the western part of the Emilia Romagna region, between the Apennines and the Po Valley. According to the Köppen climate classification [31], Parma is characterized by a humid subtropical climate (Cfa). In particular, the summers are hot and sultry, with monthly average maximum temperatures ranging about $24-27^{\circ} \mathrm{C}$ during September and June and $28-30^{\circ} \mathrm{C}$ during August and July. The monthly average minimum temperatures during summer months range $14-16{ }^{\circ} \mathrm{C}$ during September and June and $17-18{ }^{\circ} \mathrm{C}$ during August and July. Summer days are often affected by afternoon thunderstorms. The average monthly precipitations during summer range from about $50 \mathrm{~mm}$ during July (the driest month) to about $70 \mathrm{~mm}$ during September.

\subsection{Daytime and Nighttime LST}

The freely available Advanced Spaceborne Thermal Emission and Reflection Radiometer (ASTER) remote sensing data products [32] were used to estimate daytime and nighttime LST. ASTER is a multispectral imager that was provided by the Japanese Ministry of Economy, Trade and Industry (METI: Tokyo, Japan) for launch on board the National Aeronautics and Space Administration (NASA: Washington, DC, USA) Earth Observing System (EOS) Terra spacecraft in December 1999. ASTER provides high-resolution images of the planet Earth in 14 different bands of the electromagnetic spectrum, ranging from visible to thermal infrared light. In this study, the ASTER Level 1 Precision Terrain Corrected Registered At-Sensor Radiance (AST_L1T) data product [33] was used and retrieved from the online Data Pool [34], courtesy of the NASA Land Processes Distributed Active Archive Center (LP DAAC: Sioux Falls, SD, USA), USGS/Earth Resources Observation and Science (EROS) Center, Sioux Falls, SD, USA. The AST_L1T data contain calibrated at-sensor radiance, which corresponds with the ASTER Level 1B (AST_L1B) that has been geometrically corrected, and rotated to a north-up UTM projection [33]. The thermal infrared (TIR) wavelength band 14 (TIR_Band14: $\mu \mathrm{m}$ 10.950-11.650) with high-spatial resolution (90 m resolution), but low-temporal resolution (temporal frequency greater than 15 days), was used for LST estimation. In particular, the LST estimation was carried out by using a customized R code (aster_layer_calc.r) available in the section "code" of the public repository of the GitHub platform [35] that contains all data and codes developed for this work. The procedure is based on the work described at the NASA Earthdata work repository [36]. This code performs extraction and conversion of TIR_Band14 from original ASTER files and calculates the AST_L1T (spectral radiance at the sensor's aperture, $L_{\lambda}$ ) by using the relation:

$$
L_{\lambda}=(D N-1) \times U C C
$$

where $D N$ is the digital number of data stored in image's arrays; and UCC is the unit conversion coefficient $\left(\mathrm{W} \mathrm{m}^{-2} \mathrm{sr}^{-1} \mu \mathrm{m}^{-1}\right)$. 
Hence, the code provides an estimation of brightness temperatures (TB):

$$
T B=K 2 / \ln \left(K 1 / L_{\lambda}+1\right),
$$

where $K 2\left(1.273 \times 10^{3}\right)$ and $K 1\left(6.464 \times 10^{2}\right)$ are the band-specific thermal conversion constants.

Finally, LST was estimated thanks to a weighted Planck function:

$$
L S T=T B /[1+(\lambda \times T B / c 2) \times \ln (\varepsilon),
$$

where $\lambda$ is the wavelength of emitted radiance (band 14); $\varepsilon$ is the surface emissivity dimensionless (in this study 0.95 and 0.90 ); and $c 2$ is obtained by the following equation:

$$
c 2=h \times c / s=1.4388 \times 10^{-2} \mathrm{~m} \mathrm{~K}=14,388 \mu \mathrm{m} \mathrm{K},
$$

where $h$ is Planck's constant $\left(6.626 \times 10^{-34} \mathrm{~J} \mathrm{~s}\right) ; c$ is the speed of light $\left(2.998 \times 10^{8} \mathrm{~m} / \mathrm{s}\right)$; and $s$ is the Boltzmann constant $\left(1.38 \times 10^{-23} \mathrm{~J} \mathrm{~K}^{-1}\right)$.

The procedure of LST estimation used in this study follows the same scheme adopted in QGIS Semi-Automatic Classification Plugin [37]. Most roofs of residential buildings in the city of Parma are characterized by red rough bricks and, for this reason, a general emissivity value of 0.95 was considered (analyses were also carried out with an average emissivity value of 0.90 ).

In this study, six clear-sky ASTER images (four daytime and two nighttime images) clearly covering the city of Parma were acquired during the summer months (Table 1).

\begin{tabular}{|c|c|c|c|}
\hline $\begin{array}{c}\text { Date } \\
\text { (Day/Month/Year) }\end{array}$ & Time of Day & Time (h:min:s) & Meteorological Characteristics of Parma \\
\hline 25 June 2016 & Nighttime & $21: 18: 34$ & $\begin{array}{c}\mathrm{T}_{\max } 34^{\circ} \mathrm{C} ; \mathrm{T}_{\min } 23^{\circ} \mathrm{C} ; \mathrm{RH} 54 \% \text {; Wind } \\
\text { speed } 5 \mathrm{~km} / \mathrm{h} \text {; Clear sky; No precipitation }\end{array}$ \\
\hline 30 June 2015 & Daytime & 10:17:20 & $\begin{array}{c}\mathrm{T}_{\max } 30^{\circ} \mathrm{C} ; \mathrm{T}_{\min } 20^{\circ} \mathrm{C} \text {; RH } 54 \% \text {; Wind } \\
\text { speed } 7 \mathrm{~km} / \mathrm{h} \text {; Clear sky; No precipitation }\end{array}$ \\
\hline 25 July 2010 & Daytime & $10: 22: 13$ & $\begin{array}{c}\mathrm{T}_{\max } 29^{\circ} \mathrm{C} ; \mathrm{T}_{\min } 15^{\circ} \mathrm{C} ; \mathrm{RH} 42 \% \text {; Wind } \\
\text { speed } 6 \mathrm{~km} / \mathrm{h} \text {; Clear sky; No precipitation }\end{array}$ \\
\hline 3 August 2016 & Daytime & 10:17:00 & $\begin{array}{c}\mathrm{T}_{\max } 32{ }^{\circ} \mathrm{C} ; \mathrm{T}_{\min } 20^{\circ} \mathrm{C} ; \mathrm{RH} 53 \% \text {; Wind } \\
\text { speed } 6 \mathrm{~km} / \mathrm{h} \text {; Clear sky; No precipitation }\end{array}$ \\
\hline 26 August 2015 & Nighttime & $21: 18: 34$ & $\begin{array}{c}\mathrm{T}_{\max } 29^{\circ} \mathrm{C} ; \mathrm{T}_{\min } 17^{\circ} \mathrm{C} ; \mathrm{RH} 63 \% \text {; Wind } \\
\text { speed } 4 \mathrm{~km} / \mathrm{h} \text {; Clear sky; No precipitation }\end{array}$ \\
\hline 6 September 2014 & Daytime & $10: 22: 52$ & $\begin{array}{c}\mathrm{T}_{\max } 28^{\circ} \mathrm{C} ; \mathrm{T}_{\min } 18^{\circ} \mathrm{C} ; \mathrm{RH} 68 \% \text {; Wind } \\
\text { speed } 5 \mathrm{~km} / \mathrm{h} \text {; Clear sky; No precipitation }\end{array}$ \\
\hline
\end{tabular}

Table 1. The list of dates of the ASTER images selected and the corresponding daily meteorological characteristics of Parma.

$\mathrm{T}_{\max }$ and $\mathrm{T}_{\min }$ are the daily maximum and minimum temperatures, respectively; $\mathrm{RH}$ is the relative humidity.

\subsection{Urban Imperviousness}

The very high-resolution $(10 \mathrm{~m})$ urban imperviousness (or built-up-surface) indicator used in this study was provided and made freely available by ISPRA (Italian National Institute for Environmental Protection and Research) [38]. This spatial dataset covers the entire Italian territory and was developed merging information obtained by using RapidEye images and the Sentinel-2A satellite data coverages available for the year 2015, improving the previous national high-resolution $(20 \mathrm{~m})$ imperviousness cartography of the Copernicus Program [26]. In addition, the overall accuracy of the data and the image classification system was verified by using the vector information coming from OpenStreetMap data [28], the main worldwide collaborative project for free mapping. All information achieved on the spatial degree of imperviousness are finally classified into a binary product by 
applying a threshold value of 30\% following a simple rule [39]: 0-29\% = pervious surface (value $=0$ ); $30-100 \%=$ impervious surface (value $=1$ ). The areas classified as imperviousness include buildings, sheds, transport, industrial and commercial areas, recreational parks, construction sites, roads, railways, railway locations, permanent greenhouse, mining areas, landfills, and other infrastructures. The validation of this binary environmental indicator has been carried out through a comparison with the monitoring points of the national and regional impervious surfaces network, revealing an overall accuracy greater than 95\% [28]. Urban imperviousness was extracted for the municipality of Parma, one of the Italian municipalities with the highest imperviousness values (only after Rome, Milan, Turin, Naples, Venice, Ravenna and Palermo). In particular, Parma has about $23 \%$ of its municipal territory (6104 ha) classified as impervious [28]. The spatial extent of the work was provided by the Italian National Institute of Statistics (ISTAT) data using Parma's administrative boundaries [40]. Residential building's data of Parma were provided by the Emilia Romagna regional geoportal and in particular, the regional topographic database [41].

\subsection{Study Framework and Statistical Analyses}

Statistical analyses were carried out using IBM SPSS software [42] and open source R environment software [43] with specific packages for spatial data processing and mapping tasks [44-46].

The analyses are focused on residential buildings located in the municipality of Parma, also accounting for urban zones, such as typical urban (densely built-up) and park/rural areas. Urban zones were identified using the local cartography provided by Parma's municipal territorial planning sector (Settore Pianificazione Territoriale del Comune di Parma). Of the total 10,444 residential buildings available, $15.3 \%$ of data were excluded for missing or incomplete information and 8898 $(84.7 \%)$ were included in the study (Figure 1$)$.

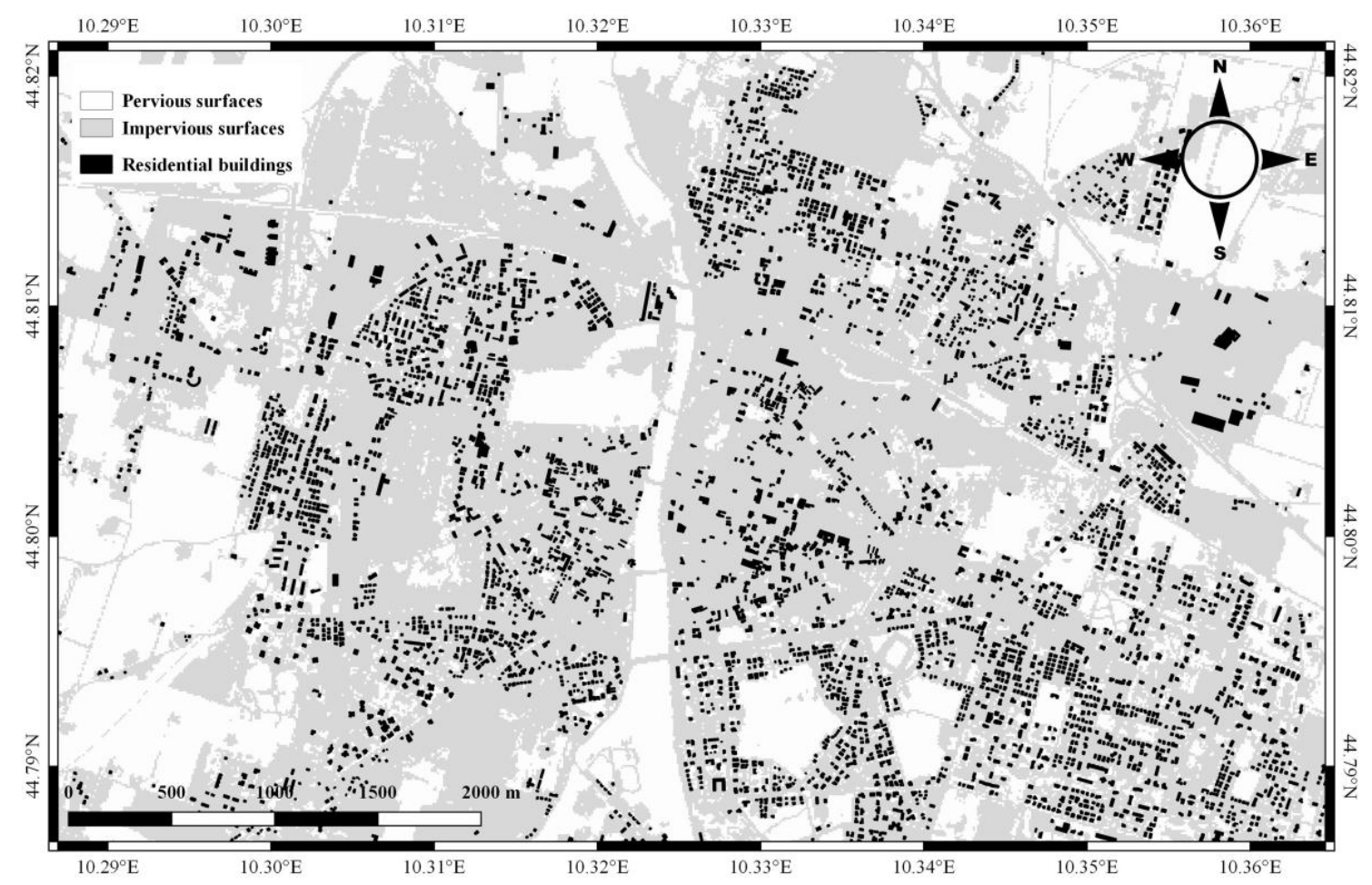

Figure 1. Map of residential buildings (black polygons) located in the city center of Parma. Impervious and pervious surfaces are indicated in grey and white, respectively.

As the ASTER-LST spatial resolution $(90 \mathrm{~m} \times 90 \mathrm{~m}$ ) (red squares in Figure 2) is not suitable for measuring exactly the building surface temperature, we have assumed that an area around each residential building exists, defined as "Building Thermal Functional Area" (BTFA), useful to lead 
building-proxy thermal analyses by using ASTER information sources. The BTFA, in function to its characteristics (i.e., the imperviousness density), could affect the building thermal status in a proportional way. The BTFA was assessed by using a circular model where its center was the building centroid (Figure 2): the radius considered was of about $56 \mathrm{~m}$, in this way defining an area (BTFA) of about 1 ha. The choice of 1 ha was based on the unit used to measure the area of a farmland and building land as reported in the European Directive 80/181/EEC [47]. For each BTFA assessed, the correspondent ASTER-LST value (ST_BTFA) was extracted by using the coordinates of the BTFA center that also corresponds to the residential building centroid (Figure 2). For each BTFA, the imperviousness density value (ID) was assessed (Figure 2).

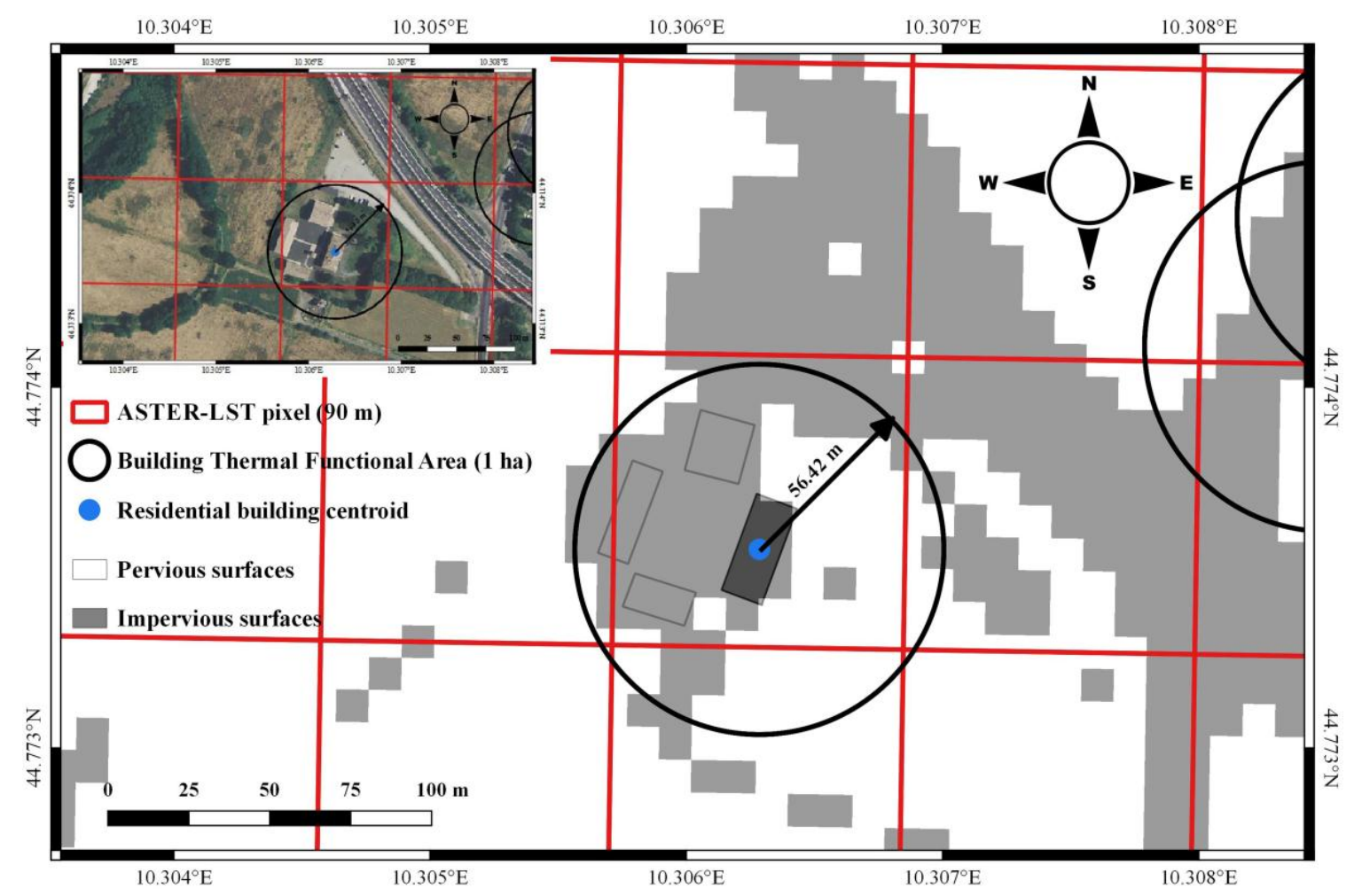

Figure 2. Building Thermal Functional Area (BTFA) framework. The black circle delimits the 1-ha residential BTFA. The blue point is the BTFA center (building centroid). Red squares represent the ASTER-LST pixels (90 $\mathrm{m}$ resolution). Impervious and pervious surfaces (10 $\mathrm{m}$ resolution) are indicated by grey and white colors respectively.

Then, the extracted daytime and nighttime ST_BTFA values were classified by using the correspondent ID value into five ID groups: (1) very low ID $\leq 20 \%$; (2) low $20 \%<$ ID $\leq 40 \%$; (3) moderate $40 \%<$ ID $\leq 60 \%$; (4) high $60 \%<$ ID $\leq 80 \%$; and (5) very high ID > $80 \%$. In this way, the average ST_BTFA for each ID group was calculated and significant ST_BTFA differences were investigated through nonparametric procedures. This choice was based on the fact that the normal distribution assumption of the ST_BTFA residuals was not always satisfied. The Kruskal-Wallis test [48] is a robust equivalent of the one-way analysis of variance (ANOVA) and it was used to compare the ST_BTFA ranks among the five ID independent groups. The Mann-Whitney U test [49] is the equivalent of the $t$-test and it was used to lead a twice-comparison of ST_BTFA medians on ID independent groups following a multi-comparison scheme.

Preliminary plotting analyses were carried out investigating the relationships between daytime and nighttime ST_BTFA and ID groups for each available ASTER image.

Subsequently, detailed descriptive and boxplot analyses investigated these relationships in typical densely urbanized and park/rural areas of the Parma municipality with the aim to evaluate if different urban zones play a role as confounder. 
Data and code functions developed for this work are available in the public repository on the GitHub platform [35].

\section{Results}

\subsection{Relationships between Daytime and Nighttime ST_BTFA and Imperviousness Density Groups}

The exploratory analyses revealed that both daytime (Figure 3) and nighttime (Figure 4) mean ST_BTFA values (as well as median values) increased significantly $(p<0.001)$ in all summer days going from the very low to the very high imperviousness density group. The steepest ID-related ST_BTFA curves were observed both during daytime and nighttime on the last days of June, a period characterized by the maximum day-length in northern hemisphere and solar irradiance. In particular, the differences between the highest and the lowest mean ST_BTFA among ID groups ( $\triangle$ ST_BTFA) were:

- $\quad 3.0{ }^{\circ} \mathrm{C}$ during daytime on 30 June (Figure 3), when $+1.0{ }^{\circ} \mathrm{C}$ per $20 \%$ increase of imperviousness density was observed; and

- $2.0^{\circ} \mathrm{C}$ during nighttime on 25 June (Figure 4 ), when $+0.7^{\circ} \mathrm{C}$ per $20 \%$ increase of imperviousness density was observed.

30-06-2015

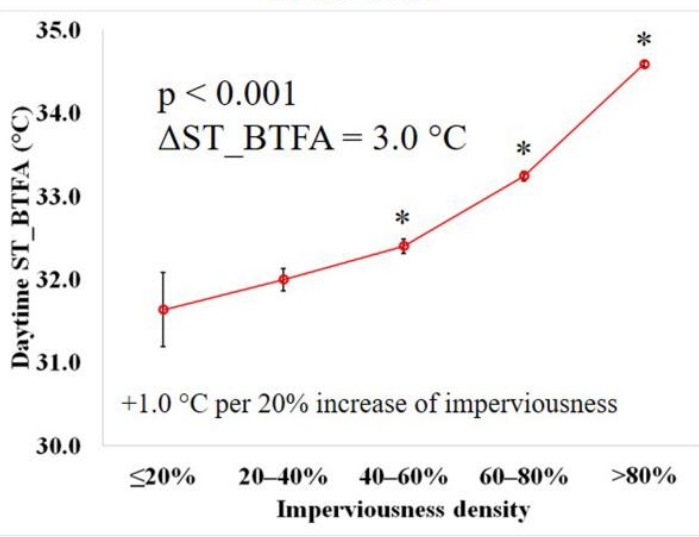

03-08-2016

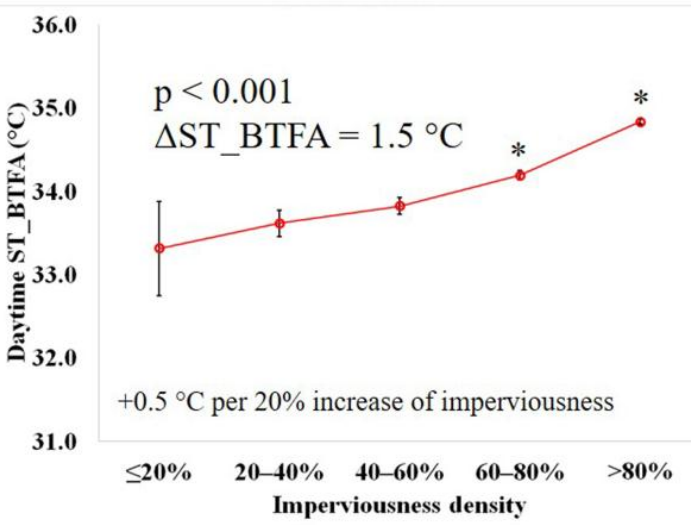

25-07-2010

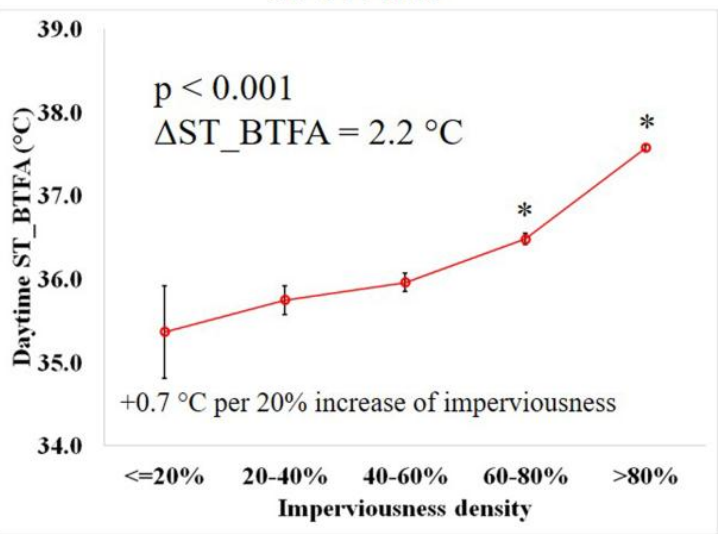

06-09-2014

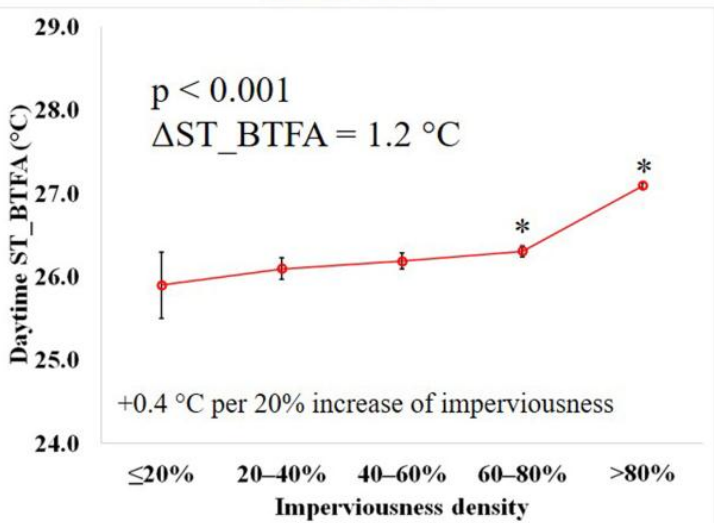

Figure 3. Relationships between daytime mean surface temperatures nearby residential buildings (ST_BTFA) and imperviousness density (ID) groups on four summer days in Parma. $\triangle$ ST_BTFA represents the difference between the highest and the lowest daytime mean ST_BTFA among ID groups. The 95\% confidence intervals for ST_BTFA means are indicated. The $p$ value was assessed by using the Kruskal-Wallis test. * indicates significant daytime ST_BTFA differences $(p<0.01)$ compared with all the other ID groups assessed with the Mann-Whitney U test. 
The steepness of the curves decreased progressively during summer, reaching the minimum at the end of August during nighttime (26 August) with a $\triangle$ ST_BTFA of $0.9^{\circ} \mathrm{C}$ (Figure 4 ) or at the beginning of September during daytime (6 September) with a $\triangle$ ST_BTFA of $1.2^{\circ} \mathrm{C}$ (Figure 3). The ST_BTFA values assessed in the high and very high ID groups were always significantly different $(p<0.01)$ from all the other ID groups both during daytime (Figure 3) and nighttime (Figure 4). In addition, the moderate ID group also revealed significant differences from all other ID groups during daytime on 30 June (Figure 3).

25-06-2016

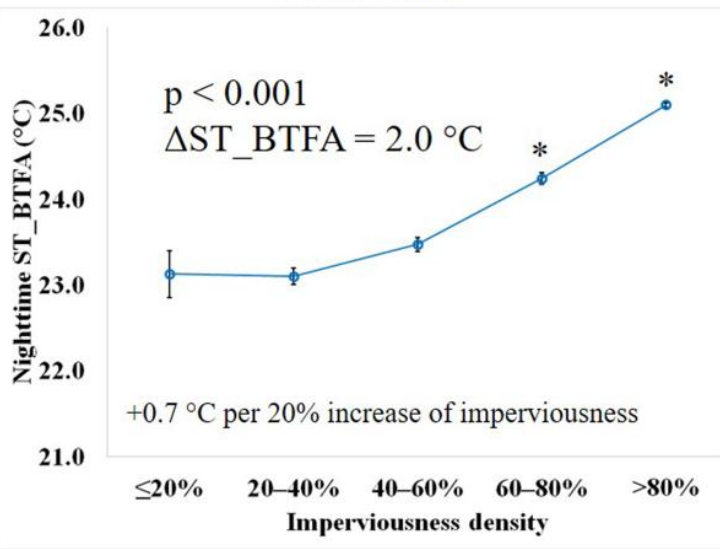

26-08-2015

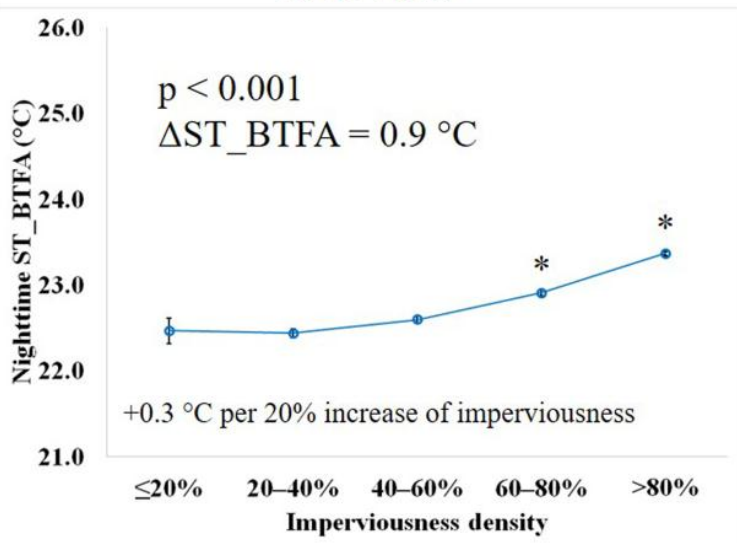

Figure 4. Relationships between nighttime mean surface temperatures nearby residential buildings (ST_BTFA) and imperviousness density (ID) groups on two summer days in Parma. $\triangle$ ST_BTFA represents the difference between the highest and the lowest nighttime mean ST_BTFA among ID groups. The $95 \%$ confidence intervals for ST_BTFA means are indicated. The $p$ value was assessed by using the Kruskal-Wallis test. * indicates significant daytime ST_BTFA differences $(p<0.01)$ compared with all the other ID groups assessed with the Mann-Whitney U test.

\subsection{Relationships between Urban and Park/Rural ST_BTFA in Different Imperviousness Density Groups}

The following results are based on the analyses of the two ASTER images (one for daytime and the other for nighttime) that in the previous exploratory analyses revealed the steepest ID-related ST_BTFA curves. In particular, the daytime ASTER image of 30 June 2015, and the nighttime ASTER image of 25 June 2016 were analyzed.

Both maps of distribution of daytime and nighttime ST_BTFA quartiles (Figures 5 and 6) revealed a prevalence of residential buildings (more than $60 \%$ and $50 \%$ during daytime and nighttime respectively) in moderate and high ID groups in the 1st ST_BTFA quartile range (27-33 $\left.{ }^{\circ} \mathrm{C}\right)$. Most buildings in the 1 st ST_BTFA quartile fell into the park/rural area (Figures 5 and 6). The situation substantially changed in the other daytime and nighttime ST_BTFA quartiles. In these cases, progressive increases of building frequencies were observed going from the 2nd to the 4th ST_BTFA quartile in the very high ID group: about $90 \%$ of buildings were observed in the 4th ST_BTFA quartile (Figures 5 and 6) also characterized by a prevalence of buildings (above 90\%) in urban area. On the other hand, very low frequencies of buildings or their total absence were observed in low and especially very low ID groups, particularly when the 3rd and 4th ST_BTFA quartiles were considered (Figures 5 and 6).

The daytime ST_BTFA values (both median and average values) revealed progressive increases in both urban and park/rural areas (Table 2). These increases were statistically significant $(p<0.01)$ going from the low ID to the very high ID group. In particular, the difference between the highest and the lowest average ST_BTFA value observed among ID groups was $3.3^{\circ} \mathrm{C}$ and $2.2{ }^{\circ} \mathrm{C}$ in urban and park/rural areas, respectively. 


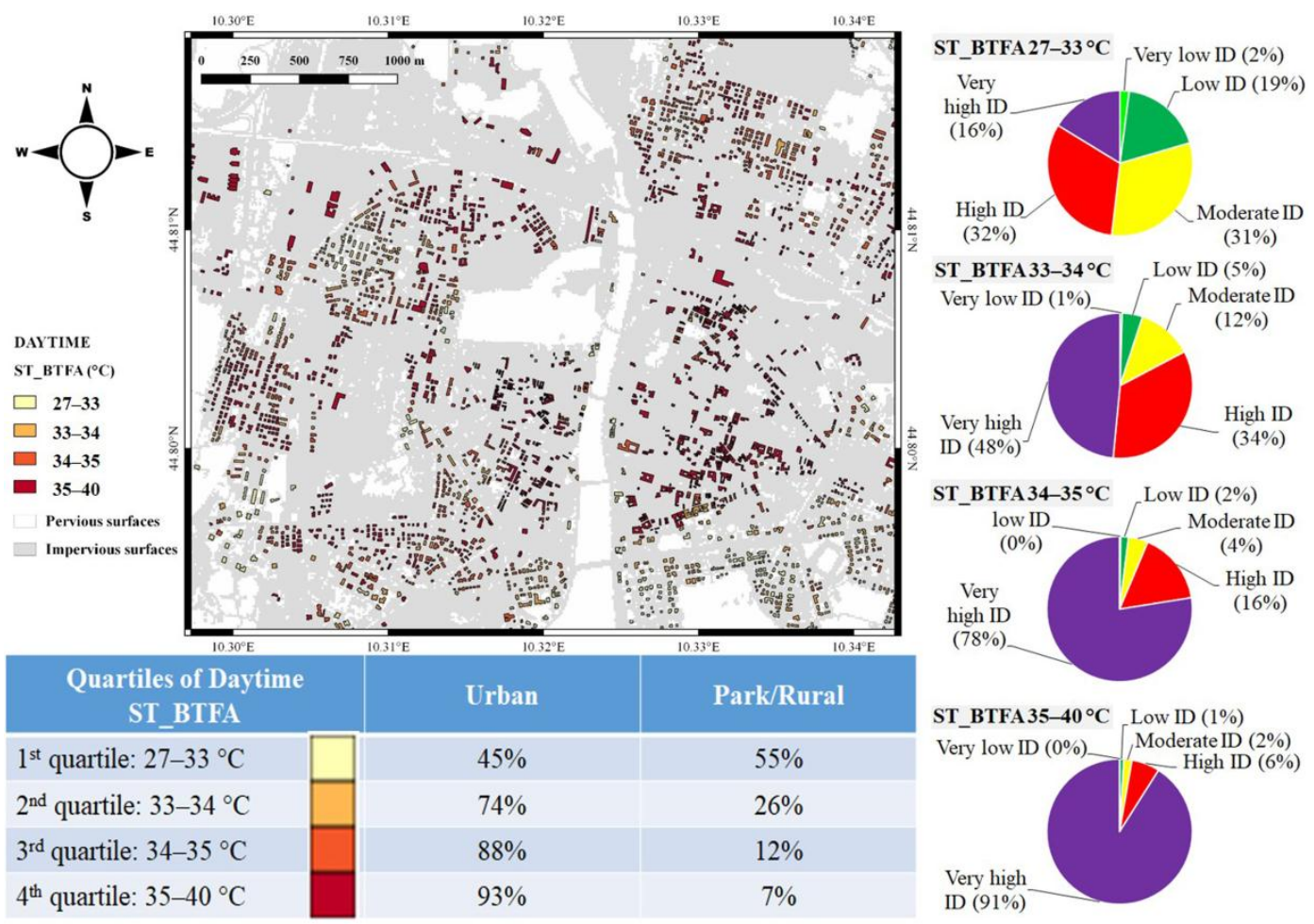

Figure 5. Maps of daytime quartiles of surface temperatures nearby residential buildings (ST_BTFA) on 30 June 2015 in the city center of Parma. The pie charts on the right show the residential building frequencies for each ST_BTFA quartile observed in different imperviousness density (ID) groups. The table shows the building frequencies for each ST_BTFA quartile observed in urban and park/rural areas.

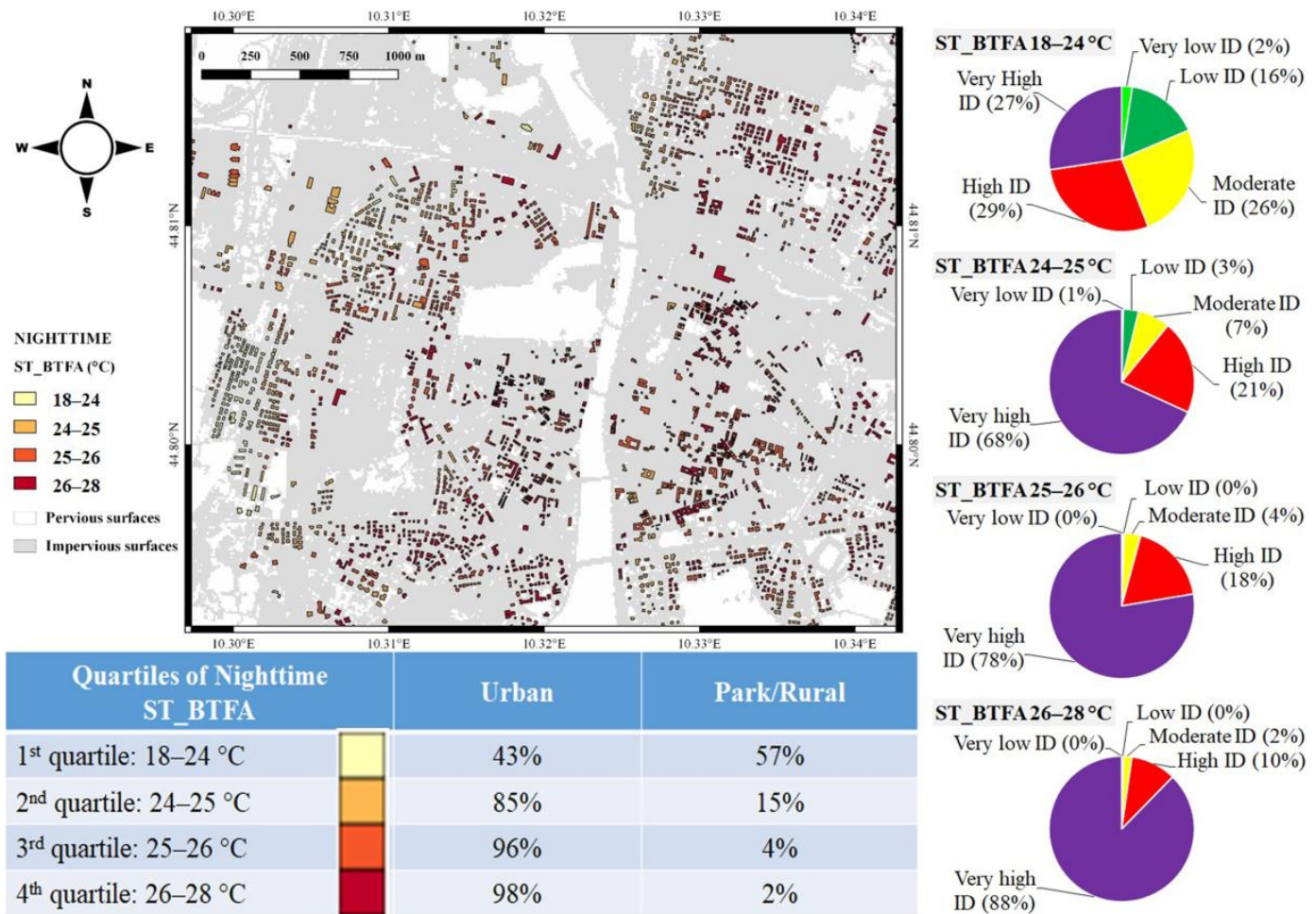

Figure 6. Maps of nighttime quartiles of surface temperatures nearby residential buildings (ST_BTFA) on 25 June 2016 in the city center of Parma. The pie charts on the right show the residential building frequencies for each ST_BTFA quartile observed in different imperviousness density (ID) groups. The table shows the building frequencies for each ST_BTFA quartile observed in urban and park/rural areas. 
A similar ST_BTFA pattern was also observed during nighttime in park/rural areas, even if the ST_BTFA variation among ID groups was less pronounced $\left(\triangle \mathrm{ST}\right.$ B BTFA of $\left.1.2^{\circ} \mathrm{C}\right)$ than daytime and they were statistically significant $(p<0.01)$ going from the moderate ID to very high ID group. A slightly different situation was observed considering the urban nighttime ST_BTFA pattern $\left(\triangle S T \_B T F A\right.$ of $\left.1.3^{\circ} \mathrm{C}\right)$ : after a not significant $(p<0.13)$ decrease of ST_BTFA from the very low ID to the low ID group, subsequent progressive significant $(p<0.05)$ ST_BTFA increases among ID groups were observed, reaching the maximum ST_BTFA value in the very high ID group (Table 2).

Table 2. Descriptive statistic of daytime (30 June 2015) and nighttime (25 June 2016) surface temperatures nearby residential buildings (ST_BTFA) observed in different urban and park/rural imperviousness density (ID) groups. The percentage of residential buildings involved in each urban and park/rural ID group is indicated in round brackets. Different letters in round brackets indicate significant $(p<0.05)$ differences between ID groups.

\begin{tabular}{|c|c|c|c|c|c|}
\hline \multirow[b]{2}{*}{ ST_BTFA $\left({ }^{\circ} \mathrm{C}\right)$} & \multicolumn{5}{|c|}{ Imperviousness Density (ID) of the Building Thermal Functional Area (BTFA) } \\
\hline & $\begin{array}{c}\text { Very Low ID } \\
\leq 20 \%\end{array}$ & $\begin{array}{l}\text { Low ID } \\
20-40 \%\end{array}$ & $\begin{array}{c}\text { Moderate ID } \\
40-60 \%\end{array}$ & $\begin{array}{c}\text { High ID } \\
60-80 \%\end{array}$ & $\begin{array}{c}\text { Very High ID } \\
>>80 \%\end{array}$ \\
\hline Daytime urban & $(0.1 \%)$ & $(1.0 \%)$ & $(4.1 \%)$ & $(14.5 \%)$ & $(55.9 \%)$ \\
\hline Median & 30.7 (a) & $32.3(\mathrm{a})$ & $32.7(b)$ & $33.3(\mathrm{c})$ & $34.7(\mathrm{~d})$ \\
\hline Average & 31.3 & 32.1 & 32.6 & 33.4 & 34.6 \\
\hline St. dev. ${ }^{1}$ & 1.5 & 1.3 & 1.4 & 1.2 & 1.1 \\
\hline $95 \%$ C.I. ${ }^{2}$ & $30.2-32.4$ & $31.9-32.4$ & $32.4-32.7$ & $33.3-33.4$ & $34.6-34.7$ \\
\hline Daytime park/rural & $(0.6 \%)$ & $(5.3 \%)$ & $(8.1 \%)$ & $(7.1 \%)$ & $(3.3 \%)$ \\
\hline Median & $31.8(\mathrm{a})$ & $32.0(\mathrm{a})$ & $32.3(b)$ & 33.1 (c) & $33.9(\mathrm{~d})$ \\
\hline Average & 31.7 & 32.0 & 32.3 & 33.0 & 33.9 \\
\hline St. dev. ${ }^{1}$ & 1.8 & 1.6 & 1.5 & 1.3 & 1.3 \\
\hline $95 \%$ C.I. $^{2}$ & $31.2-32.2$ & $31.8-32.1$ & $32.2-32.4$ & $32.9-33.1$ & $33.8-34.1$ \\
\hline Nighttime urban & $(0.1 \%)$ & $(1.0 \%)$ & $(4.1 \%)$ & $(14.5 \%)$ & $(55.9 \%)$ \\
\hline Median & $24.8(a-b-c)$ & $23.6(a)$ & $24.4(\mathrm{~b})$ & $24.9(\mathrm{c})$ & $25.4(\mathrm{~d})$ \\
\hline Average & 24.4 & 23.8 & 24.2 & 24.6 & 25.1 \\
\hline St. dev. ${ }^{1}$ & 1.1 & 1.2 & 1.1 & 1.1 & 0.9 \\
\hline $95 \%$ C.I. ${ }^{2}$ & $23.7-25.2$ & $23.5-24.1$ & $24.1-24.4$ & $24.6-24.7$ & $25.1-25.2$ \\
\hline Nighttime park/rural & $(0.6 \%)$ & $(5.3 \%)$ & $(8.1 \%)$ & $(7.1 \%)$ & $(3.3 \%)$ \\
\hline Median & $22.7(\mathrm{a})$ & $22.8(\mathrm{a})$ & 22.9 (a) & $23.1(b)$ & 23.9 (c) \\
\hline Average & 22.8 & 22.9 & 23.0 & 23.3 & 24.0 \\
\hline St. dev. ${ }^{1}$ & 0.7 & 0.8 & 0.9 & 1.0 & 1.1 \\
\hline $95 \%$ C.I. ${ }^{2}$ & $22.6-23.0$ & $22.9-23.0$ & $22.9-23.1$ & $23.2-23.4$ & $23.8-24.1$ \\
\hline
\end{tabular}

${ }^{1}$ St. dev. is the standard deviation. ${ }^{2}$ C.I. is the confidence interval.

Within the same ID group, both daytime and nighttime urban ST_BTFA values were generally significantly (prevalently $p<0.001$ ) higher than park/rural ST_BTFA values (Figure 7).

Only two exceptions were observed during daytime. In particular, not significant differences between urban and park/rural ST_BTFA were found in the very low $(p=0.416)$ and low $(p=0.296)$ ID groups. Even though a difference of about $1.0^{\circ} \mathrm{C}$ between the park/rural and the urban median values was observed during daytime in the very low ID group, the lack of significance was due to the small sample size $(N=10)$ observed in the urban environment (Figure 7). On the other hand, strongly significant $(p<0.001)$ higher urban ST_BTFA values than park/rural ones were always found during nighttime in all ID groups (Figure 7). In addition, wider ST_BTFA differences between urban and park/rural areas were observed during nighttime (the average urban ST_BTFA value was above $1{ }^{\circ} \mathrm{C}$ higher than the park/rural one) than during daytime (the average urban ST_BTFA value was about $0.5^{\circ} \mathrm{C}$ higher than the park/rural one). 

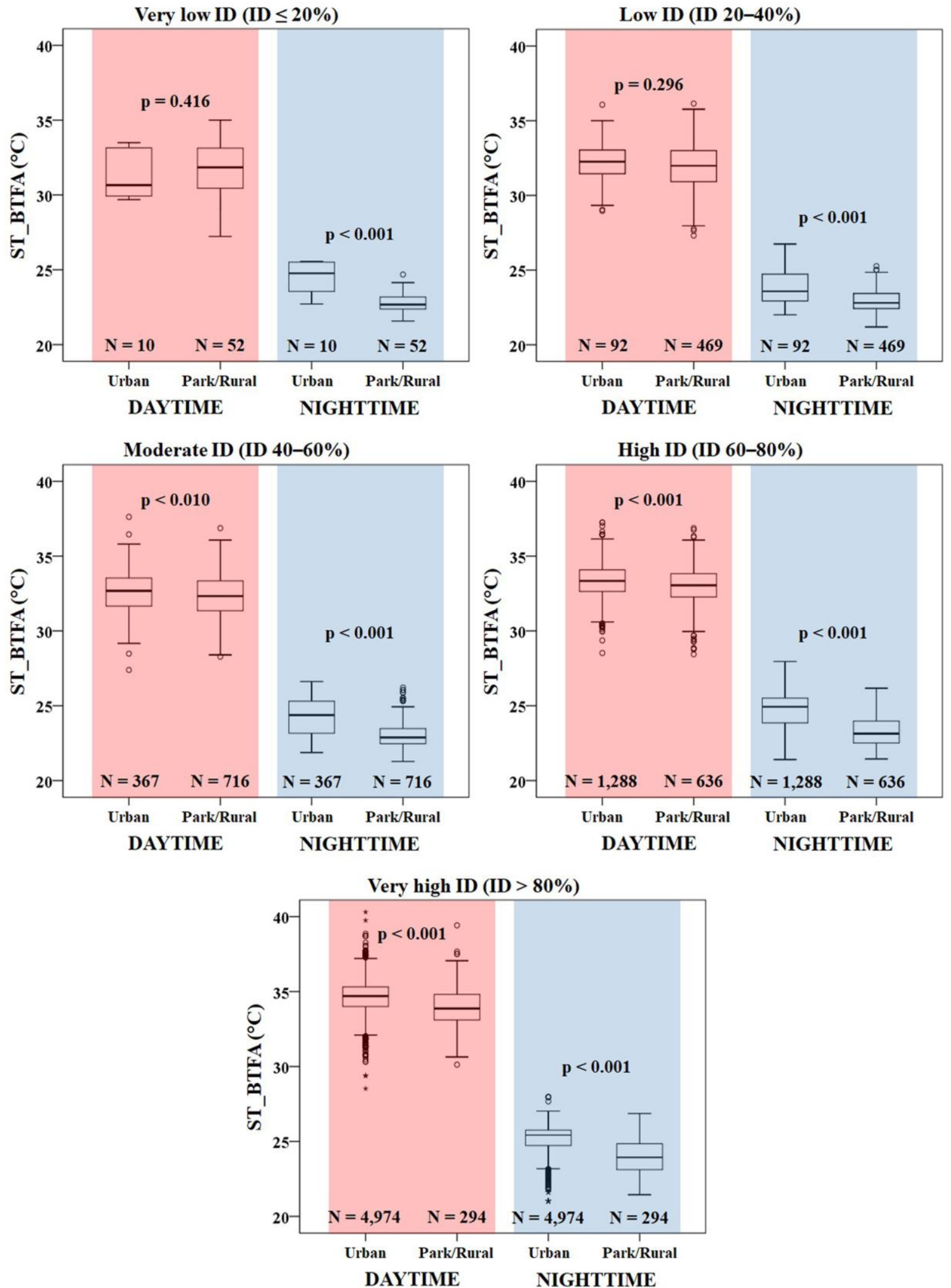

Figure 7. Boxplot charts related to the surface temperature nearby residential buildings (ST_BTFA) observed in urban and park/rural areas during daytime (highlighted in red) and nighttime (highlighted in blue) in the five imperviousness density (ID) groups. $N$ is the number of BTFA considered in different ID groups and urban zones. Significant levels ( $p$-value) between urban and park/rural ST_BTFA values were reported. 


\section{Discussion}

Close to two thirds of Europe's urban dwellers reside in small urban places (in settlements with fewer than 500,000 inhabitants) [1], which therefore represent sensitive environments towards which to pay much attention. For this reason, this study was focused on a little Italian municipality (Parma) with about 200,000 inhabitants and with a very high urban imperviousness degree: almost a quarter of its municipal territory is classified as imperviousness [28].

The main findings of this study can be summarized as follows:

1. The rise of ST_BTFA observed increasing the ID was mostly more consistent during daytime than nighttime, and in densely urban zones than park/rural zones:

a. $\quad+1.0{ }^{\circ} \mathrm{C}$ and $+0.7^{\circ} \mathrm{C}$ per $20 \%$ increase of imperviousness were observed during daytime and nighttime respectively at the end of June;

b. daytime $\triangle$ ST_BTFA among ID groups was $3.3^{\circ} \mathrm{C}$ in urban areas and $2.2^{\circ} \mathrm{C}$ in park/rural areas; and

c. nighttime $\triangle \mathrm{ST} \_\mathrm{BTFA}$ among ID groups was $1.3{ }^{\circ} \mathrm{C}$ in urban areas and $1.2{ }^{\circ} \mathrm{C}$ in park/rural areas.

2. Within the same ID group, ST_BTFA differences between urban and park/rural areas were higher during nighttime (above $1^{\circ} \mathrm{C}$ ) than during daytime (about $0.5^{\circ} \mathrm{C}$ ).

3. The strongest ID-related ST_BTFA increases were observed on days characterized by the maximum summer day-length and solar radiative load (days at the end of June).

While it is well understood that imperviousness increases surface temperatures $[17,50,51]$ and that the impervious percentage accounts for most of the LST variation in urban areas $[15,18,52,53]$, very little is known about the situation nearby residential buildings, especially when different urban zones are considered. The knowledge of how the surface temperature nearby residential buildings varies based on the surrounding imperviousness density is very important information that assumes further interest in this study where significant ST_BTFA differences between densely urban and park/rural areas were observed, also revealing different dynamics during daytime and nighttime. This finding supports results coming from previous studies where the influence of urban parks and greenspaces as cooling elements, or less warming elements, can extend several hundred meters beyond their boundaries into the built-up area [54,55]. In a recent study [19] carried out in a Chinese city, where a dramatic expansion of the urbanized area was observed in the last few years, the authors found that the urban green spaces were cooler, especially thanks to evapotranspiration, than the surrounding built-up areas, reducing their summer LST by several degrees. This information supports previous studies, which have shown negative correlation between the percentage of green vegetation and LST [53,56]. In addition, our study also revealed greatest ST_BTFA differences (above $1{ }^{\circ} \mathrm{C}$ ) between urban and park/rural areas during nighttime. This means that the cooling effect of green areas on surface temperatures nearby residential buildings is greater during nighttime, when the direct downward solar radiation contribution is null. This is in agreement with the fact that the UHI is a typically nighttime phenomenon [53,57] when the radiation stored during the day in the densely built-up areas is released into the atmosphere during the night [29]. These findings are especially useful in a country such as Italy where frequent and often intense heat waves occur during summer, and a general increased earliness in the occurrence of the most critical heat waves was observed at the end of June [58], when day-length is a risk factor with often devastating effects for the general population and especially the most vulnerable subjects $[59,60]$.

In the present study, the reliability of the high spatial resolution imagery has allowed obtaining detailed information on imperviousness-related surface temperature nearby residential buildings. This information is of particular importance in light of the fact that rooftops are the major impervious surfaces in the urban residential environment [30] and asphalt surfaces, generally located near buildings, are the land cover class that exacerbates extreme heat [53]. Our findings partly confirms what has already been highlighted in the few previous studies that have dealt with similar issues. In a 
study carried out in an American city (Phoenix) with a subtropical desert climate [61], the authors found that the presence of buildings does not explain much of the variation in LST. However, the majority of buildings in Phoenix are composed of bright materials with light color rooftops, which reflect most of incoming solar radiation and retain low amount of heat. On the other hand, in our study, most residential building roofs are characterized by red rough bricks, which reflect much less solar radiation and retain more heat. This last observation is in agreement with findings from another American study carried out in Baltimore [62], where most building are constructed with dark-colored rooftops, and also suggest that relationships between imperviousness density and surface temperature of buildings could vary significantly from city to city and within cities also based on the rooftop characteristics [61].

The strongest association between ST_BTFA and the surrounding imperviousness density particularly evident in this study on days characterized by the maximum summer solar radiative load enhanced the sunlight contribution to the thermal building balance especially during the hottest period of the year. This result supports the finding concerning the higher ID-related ST_BTFA increase observed during daytime than nighttime. This is also in agreement with Zhao et al. [30] who revealed that rooftop characteristics explain over $30 \%$ of daytime rooftop surface temperature variations and slightly more than $17 \%$ of nighttime temperatures. The authors also suggested that the direct solar insolation rather than heat retention of rooftop materials explained well the observed temperature variations. In addition, other authors [53] also revealed that greater residential building fraction increase daytime surface temperatures with insignificant nighttime impact.

The possibility to use thermal infrared images with very high spatial resolutions in this and several previous studies have allowed for better understanding of microclimate patterns at the urban level, providing useful information for local authorities, land-use decision makers, and urban planners. However, findings from this study are not generalizable and are only valid for inland cities with similar climate and urban characteristics, such as the city size, rooftop characteristics, and comparable urban imperviousness densities. Further studies should investigate these relationships in cities with different climate and urban features, also including data related the urban morphology included in the BTFA framework proposed, able to confirm these results or helping to understand other urban microclimate dynamics. The study of the urban thermal impact on sensible elements, such as residential buildings, where people and vulnerable subjects spend most of their time, represents a priority in a context of global warming. In this way, targeted interventions can be better planned, identifying exactly where the critical areas are and providing insights for UHI mitigation's actions, such as building green infrastructures near residential areas (especially trees and shrubs), set up green and cool roofs, and moreover considering alternative urban design. Each improvement in the spatial knowledge of the urban climate and the behavior of specific urban zones, especially during severe climatic events (such as heat-waves, wind storms, floods), is important to increment awareness of risk and consequently a novel potential resiliency could be reached. Following this, a next step will also be the development of a summer heat-related building risk index assessed accounting any census information (at residential building scale) available and other sociological urban data sources.

\section{Conclusions}

This fine-scale urban study carried out in a typical small Italian city represents an original effort to provide a reproducible/replicable framework for better understanding the effects of different imperviousness density levels, during summer days, on surface temperatures nearby residential buildings in different urban zones (typical densely urbanized or park/rural areas). It is a practical example of how high-resolution thermal infrared remote sensing data can be useful for urban detailed analyses, as well as investigating the situation nearby single buildings, thus improving knowledge on urban climate dynamics that regulate the interactions between urban elements, the degree of imperviousness and thermal surface modifications. 
This study confirms the hypothesis that, during a summer day, the surface temperature nearby a residential building is influenced by the surrounding imperviousness degree. In particular, significant ST_BTFA increases were observed when impervious density values grew, generating different thermal dynamics during daytime and nighttime in urban and park/rural areas. The highest ST_BTFA value was observed in summer days (with higher irradiation and day-length) when very high imperviousness densities $(>80 \%$ ) surrounding building favors the formation of particularly critical areas "urban thermal hot-spots" that, also including residential buildings, can create risky conditions above all for the city dwellers and for most vulnerable people or those not acclimatized to the heat [13]. Virtually, the presence of excessive and continuous impervious surfaces surrounding residential buildings in summer days prevent their heat loss and result in extreme heat conditions, causing what could be defined as a "building heat stroke". Fine-scale urban studies represent a major challenge in the near future for better understanding the relationships between microclimate conditions and small area urban characteristics helpful to improve the UHI mitigation strategies. For individual structures such as residential buildings, cooler summer conditions due to the effect of nearby parks or any greenspaces can represent reliable UHI mitigation actions addressed to enhance the urban ecosystem and favoring a range of human health benefits. This is a priority because of the rapid and unplanned urban growth as well as the ongoing trends in global warming. In particular, the consequent increase in the frequency and intensity of heat-waves in urban environment [58] necessitate thorough and detailed investigations on the effect of urbanization on the urban thermal environment to provide effective summer UHI mitigation strategies.

Acknowledgments: This study was supported and funded by the Regional MeteoSaluteProject, Regional Health System of Tuscany DGR. N. 950 of 2004(2004DG00000001286). The AST_L1T data product was retrieved from the online Data Pool, courtesy of the NASA Land Processes Distributed Active Archive Center (LP DAAC), USGS/Earth Resources Observation and Science (EROS) Center, Sioux Falls, South Dakota, USA, https://lpdaac. usgs.gov/data_access/data_pool.

Author Contributions: Marco Morabito and Alfonso Crisci conceived and designed the experiments; Marco Morabito, Alfonso Crisci, Michele Munafò, Teodoro Georgiadis, Simone Orlandini, Patrizia Rota and Michele Zazzi performed the experiments; Marco Morabito, Alfonso Crisci, Michele Munafò, and Luca Congedo analyzed the data; and Marco Morabito, Alfonso Crisci, Luca Congedo, Patrizia Rota and Michele Zazzi contributed analysis tools and data organizations. All authors contributed to writing the paper.

Conflicts of Interest: The authors declare no conflict of interest. The founding sponsors had no role in the design of the study; in the collection, analyses, or interpretation of data; in the writing of the manuscript, and in the decision to publish the results.

\section{References}

1. United Nations, Department of Economic and Social Affairs, Population Division. World Urbanization Prospects: The 2014 Revision, Highlights ST/ESA/SER.A/352. Available online: https:/ / esa.un.org/unpd/ wup/publications / files / wup2014-highlights.Pdf (accessed on 3 October 2017).

2. European Commission. Guidelines on Best Practice to Limit, Mitigate or Compensate Soil Sealing. Brussels, 12.4.2012, SWD, 101 Final. Available online: http://ec.europa.eu/environment/soil/pdf/soil_sealing guidelines_en.pdf (accessed on 3 October 2017).

3. European Environment Agency (EEA). The European Environment-State and Outlook 2015: Synthesis Report; European Environment Agency: Copenhagen, Denmark, 2015; ISBN 978-92-9213-515-7.

4. Prokop, G.; Jobstmann, H.; Schönbauer, A. Report on Best Practices for Limiting Soil Sealing and Mitigating Its Effects; European Commission: Brussels, Belgium, 2011; 231p.

5. Artmann, M. Assessment of Soil Sealing Management Responses, Strategies, and Targets Toward Ecologically Sustainable Urban Land Use Management. Ambio 2014, 43, 530-541. [CrossRef] [PubMed]

6. Oke, T. City size and the urban heat island. Atmos. Environ. 1973, 7, 769-779. [CrossRef]

7. McGregor, G.R.; Bessemoulin, P.; Ebi, K.L.; Menne, B. Heatwaves and Health: Guidance on Warning-System Development; World Meteorological Organization and World Health Organization: Geneva, Switzerland, 2015; ISBN 978-92-63-11142-5. Available online: http:/ / www.who.int/globalchange/publications/WMO_ WHO_Heat_Health_Guidance_2015.pdf (accessed on 5 May 2017). 
8. Ward, K.; Lauf, S.; Kleinschmit, B.; Endlicher, W. Heat waves and urban heat islands in Europe: A review of relevant drivers. Sci. Total Environ. 2016, 569, 527-539. [CrossRef] [PubMed]

9. Wangpattarapong, K.; Maneewan, S.; Ketjoy, N.; Rakwichian, W. The impacts of climatic and economic factors on residential electricity consumption of Bangkok Metropolis. Energy Build. 2008, 40, 1419-1425. [CrossRef]

10. Van Vliet, M.T.H.; Yearsley, J.R.; Ludwig, F.; Vögele, S.; Lettenmaier, D.P.; Kabat, P. Vulnerability of US and European electricity supply to climate change. Nat. Clim. Chang. 2012, 2, 676-681. [CrossRef]

11. Qaid, A.; Lamit, H.B.; Ossen, D.R.; Shahminan, R.N.R. Urban heat island and thermal comfort conditions at micro-climate scale in a tropical planned city. Energy Build. 2016, 133, 577-595. [CrossRef]

12. Gabriel, K.M.A.; Endlicher, W.R. Urban and rural mortality rates during heat waves in Berlin and Brandenburg, Germany. Environ. Pollut. 2011, 159, 2044-2050. Available online: http://www. theurbanclimatologist.com/uploads/4/4/2/5/44250401/urbanruralmortality.pdf (accessed on 6 October 2017). [CrossRef] [PubMed]

13. Morabito, M.; Crisci, A.; Gioli, B.; Gualtieri, G.; Toscano, P.; Di Stefano, V.; Orlandini, S.; Gensini, G.F. Urban-hazard risk analysis: Mapping of heat-related risks in the elderly in major Italian cities. PLoS ONE 2015, 10, e0127277. [CrossRef] [PubMed]

14. Chen, X.-L.; Zhao, H.-M.; Li, P.-X.; Yin, Z.-Y. Remote sensing image-based analysis of the relationship between urban heat island and land use/cover changes. Remote Sens. Environ. 2006, 104, 133-146. [CrossRef]

15. Yuan, F.; Bauer, M.E. Comparison of impervious surface area and normalized difference vegetation index as indicators of surface urban heat island effects in Landsat imagery. Remote Sens. Environ. 2007, 106, 375-386. [CrossRef]

16. Xiong, Y.; Huang, S.; Chen, F.; Ye, H.; Wang, C.; Zhu, C. The Impacts of Rapid Urbanization on the Thermal Environment: A Remote Sensing Study of Guangzhou, South China. Remote Sens. 2012, 4, 2033-2056. [CrossRef]

17. Bektaş Balçik, F. Determining the impact of urban components on land surface temperature of Istanbul by using remote sensing indices. Environ. Monit. Assess. 2014, 186, 859-872. [CrossRef] [PubMed]

18. Grover, A.; Singh, R.B. Monitoring Spatial Patterns of Land Surface Temperature and Urban Heat Island for Sustainable Megacity: A Case Study of Mumbai, India, Using Landsat TM Data. Environ. Urban. ASIA 2016, 7, 38-54. [CrossRef]

19. Zhang, X.; Wang, D.; Hao, H.; Zhang, F.; Hu, Y. Effects of Land Use/Cover Changes and Urban Forest Configuration on Urban Heat Islands in a Loess Hilly Region: Case Study Based on Yan'an City, China. Int. J. Environ. Res. Public Health 2017, 26, 14. [CrossRef] [PubMed]

20. Wu, C. Quantifying high-resolution impervious surfaces using spectral mixture analysis. Int. J. Remote Sens. 2009, 30, 2915-2932. [CrossRef]

21. Lu, D.; Weng, Q. Extraction of urban impervious surfaces from IKONOS imagery. Int. J. Remote Sens. 2009, 30, 1297-1311. [CrossRef]

22. Lu, D.; Hetrick, S.; Moran, E. Impervious surface mapping with Quickbird imagery. Int. J. Remote Sens. 2011, 32, 2519-2533. [CrossRef] [PubMed]

23. Weng, Q. Remote sensing of impervious surfaces in the urban areas: Requirements, methods, and trends. Remote Sens. Environ. 2012, 117, 34-49. [CrossRef]

24. Zhang, Y.; Guindon, B. Multispectral analysis for manmade surface extraction from RapidEye and SPOT5. Can. J. Remote Sens. 2012, 38, 180-196. [CrossRef]

25. Zhang, H.; Jing, X.-M.; Chen, J.-Y.; Li, J.-J.; Schwegler, B. Characterizing Urban Fabric Properties and Their Thermal Effect Using QuickBird Image and Landsat 8 Thermal Infrared (TIR) Data: The Case of Downtown Shanghai, China. Remote Sens. 2016, 8, 541. [CrossRef]

26. Congedo, L.; Sallustio, L.; Munafò, M.; Ottaviano, M.; Tonti, D.; Marchetti, M. Copernicus high-resolution layers for land cover classification in Italy. J. Maps 2016, 12, 1195-1205. [CrossRef]

27. Munafò, M.; Assennato, F.; Congedo, L.; Luti, T.; Marinosci, I.; Monti, G.; Riitano, N.; Sallustio, L.; Strollo, A.; Tombolini, I.; et al. II Consumo di Suolo in Italia. Edizione 2015. Rapporti 218/2015; Istituto Superiore per la Protezione e la Ricerca Ambientale (ISPRA): Roma, Italy, 2015; ISBN 978-88-448-0703-0.

28. ISPRA. Consumo di Suolo, Dinamiche Territoriali e Servizi Ecosistemici. Edizione 2016. Rapporti 248/2016; Istituto Superiore per la Protezione e la Ricerca Ambientale (ISPRA): Roma, Italy, 2016; ISBN 978-88-448-0776-4. 
29. Morabito, M.; Crisci, A.; Messeri, A.; Orlandini, S.; Raschi, A.; Maracchi, G.; Munafò, M. The impact of built-up surfaces on land surface temperatures in Italian urban areas. Sci. Total Environ. 2016, 551, 317-326. [CrossRef] [PubMed]

30. Zhao, Q.; Myint, S.W.; Wentz, E.A.; Fan, C. Rooftop Surface Temperature Analysis in an Urban Residential Environment. Remote Sens. 2015, 7, 12135-12159. [CrossRef]

31. Rubel, F.; Kottek, M. Observed and projected climate shifts 1901-2100 depicted by world maps of the Köppen-Geiger climate classification. Meteorol. Z. 2010, 19, 135-141. [CrossRef]

32. Advanced Spaceborne Thermal Emission and Reflection Radiometer (ASTER). Available online: https: / / asterweb.jpl.nasa.gov/index.asp (accessed on 12 October 2017).

33. ASTER Level 1 Precision Terrain Corrected Registered At-Sensor Radiance-Land Processes Distributed Active Archive Center (LP DAAC). Available online: https:/ / lpdaac.usgs.gov/dataset_discovery/aster/ aster_products_table/ast_11t (accessed on 12 October 2017).

34. Data Pool-Land Processes Distributed Active Archive Center (LP DAAC). Available online: https://lpdaac. usgs.gov/data_access / data_pool (accessed on 12 October 2017).

35. GitHub Repository_Parma_Urban_Imperviouness. Available online: https://github.com/meteosalute/ Parma_urban_imperviousness (accessed on 24 October 2017).

36. Git Service Repository (Bitbucket)_LP DAAC Data User Resources/ASTER L1T. Available online: https: / / git.earthdata.nasa.gov/ projects/LPDUR/repos/aster-11t/browse (accessed on 26 November 2017).

37. Congedo, L. Semi-Automatic Classification Plugin Documentation. Release 5.3.6.1. 2017. Available online: http:/ / dx.doi.org/10.13140/RG.2.2.29474.02242/1 (accessed on 26 November 2017).

38. National Environmental Information System Network-National Imperviousness Cartography. Available online: http:/ / www.sinanet.isprambiente.it/it/sia-ispra/download-mais/consumo-di-suolo/ carta-nazionale-consumo-suolo (accessed on 12 October 2017).

39. Maucha, G.; Büttner, G.; Kosztra, B. European Validation of GMES FTS Soil Sealing Enhancement Data. In Proceedings of the 31st European Association of Remote Sensing Laboratories Symposium (EARSeL 2011): Remote Sensing and Geoinformation not Only for Scientific Cooperation, Prague, Czech Republic, 30 May2 June 2011; pp. 223-238.

40. Confini Delle Unità Amministrative a Fini Statistici. Available online: https://www.istat.it/it/archivio/ 124086 (accessed on 12 October 2017).

41. E-R Geoportale-DBTR2013-Edificio-(EDI_GPG). Available online: http://geoportale.regione.emiliaromagna.it/it/catalogo/dati-cartografici/cartografia-di-base/database-topografico-regionale/immobili/ edificato/dbtr2013-edificio-edi_gpg/?searchterm=edifici (accessed on 12 October 2017).

42. IBM Corp. IBM SPSS Statistics for Windows; IBM Corp: Armonk, NY, USA, 2016.

43. R Core Team. R: A Language and Environment for Statistical Computing; R Foundation for Statistical Computing: Vienna, Austria, 2017. Available online: http:/ / www.R-project.org/ (accessed on 12 October 2017).

44. Bivand, R.; Tim Keitt, T.; Rowlingson, B. Rgdal: Bindings for the 'Geospatial' Data Abstraction Library. R Package Version 1.2-13. 2017. Available online: https:/ / cran.r-project.org/web/packages/rgdal/index. html (accessed on 12 October 2017).

45. Hijmans, R.J. Raster: Geographic Data Analysis and Modeling. R Package Version 2.5-8. 2016. Available online: https: / cran.r-project.org/web/packages/raster/index.html (accessed on 12 October 2017).

46. Bivand, R.; Rundel, C. Rgeos: Interface to Geometry Engine-Open Source ('GEOS’). R Package Version 0.3-25. Available online: https://cran.r-project.org/web/packages/rgeos/index.html (accessed on 12 October 2017).

47. European Council Directive 80/181/EEC of 20 December 1979 on the Approximation of the Laws of the Member States Relating to Units of Measurement and on the Repeal of Directive 71/354/EEC. Journal of the European Communities No L 39/40 Official. Available online: http:/ / eur-lex.europa.eu/legal-content/en/ ALL/?uri=CELEX:31980L0181 (accessed on 14 December 2017).

48. Kruskal, W.H.; Wallis, W.A. Use of ranks in one-criterion variance analysis. J. Am. Stat. Assoc. 1952, 47, 583-621. [CrossRef]

49. Mann, H.B.; Whitney, D.R. On a test of whether one of two random variables is stochastically larger than the other. Ann. Math. Stat. 1947, 18, 50-60. [CrossRef] 
50. Essa, W.; van der Kwast, J.; Verbeiren, B.; Batelaan, O. Downscaling of thermal images over urban areas using the land surface temperature-impervious percentage relationship. Int. J. Appl. Earth Obs. Geoinf. 2013, 23, 95-108. [CrossRef]

51. Mallick, J.; Rahman, A.; Singh, C.K. Modeling urban heat islands in heterogeneous land surface and its correlation with impervious surface area by using night-time ASTER satellite data in highly urbanizing city, Delhi-India. Adv. Space Res. 2013, 52, 639-655. [CrossRef]

52. Essa, W.; Verbeiren, B.; Van der Kwast, J.; Batelaan, O. Evaluation of DisTrad thermal sharpening for urban areas. Int. J. Appl. Earth Obs. Geoinf. 2012, 19, 163-172. [CrossRef]

53. Myint, S.W.; Wentz, E.A.; Brazel, A.J.; Quattrochi, D.A. The impact of distinct anthropogenic and vegetation features on urban warming. Landsc. Ecol. 2013, 28, 959-978. [CrossRef]

54. Upmanis, H.; Eliasson, I.; Lindqvist, S. The influence of green areas on nocturnal temperatures in a high latitude city (Göteborg, Sweden). Int. J. Climatol. 1998, 18, 681-700. [CrossRef]

55. Dimoudi, A.; Nikolopoulou, M. Vegetation in the urban environment: Microclimatic analysis and benefits. Energy Build. 2003, 35, 69-76. [CrossRef]

56. Zhou, W.; Qian, Y.; Li, X.; Li, W.; Han, L. Relationships between land cover and the surface urban heat island: Seasonal variability and effects of spatial and thematic resolution of land cover data on predicting land surface temperatures. Landsc. Ecol. 2014, 29, 153-167. [CrossRef]

57. Arnfield, A.J. Two decades of urban climate research: A review of turbulence, exchanges of energy and water, and the urban heat island. Int. J. Climatol. 2003, 23, 1-26. [CrossRef]

58. Morabito, M.; Crisci, A.; Messeri, A.; Messeri, G.; Betti, G.; Orlandini, S.; Raschi, A.; Maracchi, G. Increasing Heatwave Hazards in the Southeastern European Union Capitals. Atmosphere 2017, 8, 115. [CrossRef]

59. Benmarhnia, T.; Kihal-Talantikite, W.; Ragettli, M.S.; Deguen, S. Small-area spatiotemporal analysis of heatwave impacts on elderly mortality in Paris: A cluster analysis approach. Sci. Total Environ. 2017, 592, 288-294. [CrossRef] [PubMed]

60. Xiao, J.; Spicer, T.; Jian, L.; Yun, G.Y.; Shao, C.; Nairn, J.; Fawcett, R.J.B.; Robertson, A.; Weeramanthri, T.S. Variation in Population Vulnerability to Heat Wave in Western Australia. Front. Public Health 2017, 5, 64. [CrossRef] [PubMed]

61. Zheng, B.; Myint, S.W.; Fan, C. Spatial configuration of anthropogenic land cover impacts on urban warming. Landsc. Urban Plann. 2014, 130, 104-111. [CrossRef]

62. Zhou, W.; Huang, G.; Cadenasso, M.L. Does spatial configuration matter? Understanding the effects of land cover pattern on land surface temperature in urban landscapes. Landsc. Urban Plann. 2011, 102, 54-63. [CrossRef]

(C) 2017 by the authors. Licensee MDPI, Basel, Switzerland. This article is an open access article distributed under the terms and conditions of the Creative Commons Attribution (CC BY) license (http://creativecommons.org/licenses/by/4.0/). 